\title{
Modified recombinant adenoviruses increase porcine circovirus 2 capsid protein expression and induce enhanced immune responses in mice
}

\author{
D. L. LI, Y. HUANG, L. L. CHANG, Q. DU, Y. CHEN, T. T. WANG, X. M. LUO, X. M. ZHAO, D. W. TONG*
}

College of Veterinary Medicine, Northwest A\&F University, Yangling, Shaanxi 712100, P. R. China

Received August 10, 2015; revised December 18, 2015; accepted July 04, 2016

\begin{abstract}
Summary. - Porcine circovirus type 2 (PCV2) is the primary viral pathogen of porcine circovirus associated disease (PCVAD) and vaccination is an important method to prevent and control the disease. The expression of PCV2 capsid protein (Cap) in adenovirus vector system has been investigated, but the poor immune responses limit its application. In this study, transcriptional enhancer element largest intron of the human cytomegalovirus (Intron A) and woodchuck hepatitis virus post-transcriptional regulatory element (WPRE) were applied to increase the immunogenicity of PCV2 Cap adenovirus-based vaccine. Western blot and indirect immunofluorescence assay (IFA) analysis showed that modified adenoviruses with Intron A and WPRE alone or both could significantly increase the expression of Cap compared to the unmodified adenoviruses. Furthermore, the humoral and cellular immune responses of the constructed recombinant adenoviruses were evaluated in mice. Indirect ELISA, virus neutralizing test and western blot showed that modified adenoviruses elicited higher humoral immune responses than unmodified adenovirus, and Intron A-WPRE-modified virus immunized group had better immune response than the others. Besides, the results of lymphocyte proliferation response and cytokines release assay showed that enhanced cellular immune responses were induced by modified adenoviruses. These results demonstrated that Intron A and WPRE significantly improved the expression of the Cap protein in adenovirus vector system and enhanced the immune responses in mice, making the adenovirus vector system more applicable against PCV2.
\end{abstract}

Keywords: modified recombinant adenoviruses; porcine circovirus type 2; capsid protein; immune responses

\section{Introduction}

Porcine circovirus type 2 (PCV2), a primary pathogen of porcine circovirus associated disease (PCVAD), results in great economic losses in pig industry (Opriessnig et al., 2007). Four open reading frames (ORFs) were identified as functional genes within PCV2 genome, identified as ORF1,

"Corresponding author. E-mail: dwtong@nwsuaf.edu.cn; phone: +86-29-8709-1622.

Abbreviations: iELISA = indirect enzyme-linked immunosorbent assay; PCV2 = porcine circovirus type 2 ; PCVAD = porcine circovirus associated disease; $\mathrm{VN}=$ virus neutralization assay; $\mathrm{WPRE}=$ woodchuck hepatitis virus post-transcriptional regulatory element
ORF2, ORF3 and ORF4, of which ORF1 and ORF2 are the two major ORFs (Lv et al., 2014). ORF1 encoding replicase proteins is associated with virus replication (Beach and Meng, 2012), while ORF2 encodes the unique structural protein of PCV2, capsid (Cap) protein, which is responsible for virus assembly (Mankertz et al., 2000; Nawagitgul et al., 2000). In addition, Cap protein is the main immunogen of PCV2 and contains type-specific antigenic epitopes, thus the Cap protein is usually used to develop vaccines against PCVAD (Khayat et al., 2011; Misinzo et al., 2006; Shang et al., 2009). Although some commercial PCV2 vaccines have been available and played certain roles in preventing PCVAD, it is still needed to further improve efficacy of PCV2 vaccines for eradicating PCVAD in field (Beach and Meng, 2012).

The adenovirus (Ad) expression system, one of the most widely-used viral expression systems, shows more advan- 
tages than other systems, such as easy construction, higher efficiency of gene transfer, higher titers and induction of humoral, mucosal and cellular immune responses (Benihoud et al., 1999; Douglas, 2007; Ferreira et al., 2005; Kovesdi et al., 1997; Thacker et al., 2009). Adenovirus vector system expressing PCV2 Cap protein has been studied, but has limited immune efficiency (Wang et al., 2006, 2007). One possible reason is that many proteins of adenovirus itself could induce strong immune responses, resulting in poor efficacy (Yang et al., 1995). So it is necessary to reduce the immunogenicity of adenovirus itself.

Largest intron of the human cytomegalovirus (Intron A) is a powerful transcriptional regulatory element which can increase the transgene expression (Bissonnette et al., 2006; Choi et al., 1991; Niwa et al., 1990). Woodchuck hepatitis virus post-transcriptional regulatory element (WPRE), a powerful enhancer, can improve targeted gene expression by modifying RNA polyadenylation, export and/or translation. Both of them have been widely used to improve the expression of various proteins (Li et al., 2012; Mariati et al., 2010; Sridhar et al., 2008). In previous study, some researchers have found that a 700 fold increase in the level of luciferase expression using an adenovirus construct with intron A and WPRE compared to the traditional adenovirus system (Xu et al., 2002, 2003). We therefore investigated whether these two elements could be applied to improve the immune responses to PCV2 Cap protein in adenovirus.

In this study, we attempted to construct the recombinant adenoviruses expressing PCV2 Cap protein modified with Intron A and WPRE, alone or both, and examined the immune responses in mice. Our results showed that Intron A and WPRE could improve the Cap expression in adenovirus and could enhance the humoral and cellular immune responses to PCV2 Cap in mice.

\section{Materials and Methods}

Viruses, cell lines and antibodies. Porcine circovirus type 2 (PCV2) (GenBank No. EU366323) was used in this study. Porcine kidney 15 (PK15) cell line free of porcine circovirus type 1 (PCV1) and human embryonic kidney 293 (HEK293) cell line (ATCC, CRL-1573) were cultured in Dulbecco Minimal Essential Medium (DMEM, Gibco BRL, USA) with 10\% heat-inactivated FBS (Gibco $\mathrm{BRL})$ at $37^{\circ} \mathrm{C}$ in an incubator with $5 \% \mathrm{CO}_{2}$. The rabbit anti-Cap polyclonal antibody was prepared by the standard procedures in our lab (data not shown).

Recombinant adenovirus construction. The ORF2 gene (without the nuclear localization signal peptide of 41 amino acid residues at $\mathrm{N}$-terminus) was amplified from PCV2 strain. The fragment was cloned into the puc57 plasmid (GenScript, China) and named as puc-Cap. The Intron A element (nucleotides 1265-2088; GenBank No. M60321) and WPRE element (nucleotides 1095-1670;
GenBank No. M18752) were synthesized by GenScript (Nanjing, China). Intron A was inserted upstream of the Cap using KpnI and XbaI sites, WPRE was inserted downstream of the Cap by SalI and HindIII sites, and designated as puc-Intron A-Cap-WPRE. Four fragments (Cap, IntronA-Cap, Cap-WPRE and Intron A-CapWPRE) were amplified from the puc-Intron A-Cap-WPRE, with XhoI upstream and EcoRV downstream of the fragment. Amplicons were digested with XhoI and EcoRV and cloned into the transfer vector PShuttle-CMV following the instructions of AdEasy ${ }^{\text {ix }}$ Adenoviral vector system (Agilent Technologies, USA). The recombinant plasmids, designated as PS-C, PS-A-C, PS-C-W, and PS-A-C-W, were verified by PCR, XhoI and EcoRV digestion and sequencing (Fig. 1). PmeI-linearized plasmids (PS-C, PS-A-C, PS-C-W, and PS-A-C-W) were co-transformed into E. coli bacteria strain BJ5183 with pAdEasy-1 vector by electroporation with a Bio-Rad Gene Pulser at $2.5 \mathrm{kV}, 25 \mu \mathrm{F}$ and $200 \Omega$. The transformed bacteria were plated onto LB plate with $50 \mu \mathrm{g} / \mathrm{ml}$ kanamycin and cultured at $37^{\circ} \mathrm{C}$ for $18 \mathrm{hr}$. Then the recombinant plasmids, named as rAd-C, rAd-A-C, rAd-C-W, and rAd-A-C-W, were extracted from the culture medium and verified by PCR. A plasmid without Cap was also constructed and named rAd-wild. Primers for PCR are listed in Table 1. The reaction was done in a thermocycler under the following conditions: initial denaturation at $94^{\circ} \mathrm{C}$ for $5 \mathrm{~min}$, then 30 cycles of denaturation at $94^{\circ} \mathrm{C}$ for $30 \mathrm{sec}$, annealing at $56^{\circ} \mathrm{C}$ for 30 sec and extension at $72^{\circ} \mathrm{C}$ for $2 \mathrm{~min}$, and then final polymerization at $72^{\circ} \mathrm{C}$ for another $10 \mathrm{~min}$.

Transfection and isolation of recombinant adenoviruses. HEK293 cells were seeded in a 24-well plate over night before being transfected with $2 \mu \mathrm{g}$ of recombinant plasmids (rAd-C, rAd-A-C, rAd-C-W, rAd-A-C-W and rAd-wild) digested with enzyme PacI by applying Lipofectamine 2000 transfection reagent (Invitrogen, USA) to each well. The viruses were collected 10 days later when cytopathic effect (CPE) appeared, propagated in HEK293 cells and purified thrice with plaque assay. Virus passaged until the fifth generation was titrated by the method of tissue culture infectious dose $50\left(\mathrm{TCID}_{50}\right)$.

Western blot. HEK293 cells were cultured in 6-well plates over night. Then the cells were inoculated with four recombinant adenoviruses at MOI of 20 for $30 \mathrm{hr}$. Lysates were separated by $10 \%$ SDS-PAGE and transferred to nitrocellulose membrane. Wild-type adenovirus and PBS-treated cells were regarded as control. Membrane was blocked in the blocking solution (5\% fat-free milk in PBS) at $4^{\circ} \mathrm{C}$ over night, followed by incubation with rabbit anti-PCV2 serum for $1 \mathrm{hr}$ at room temperature and then incubated with goat anti-rabbit IgG antibody conjugated with horseradish peroxidase (HRP) (Boshide, China) for $1 \mathrm{hr}$. Detection was conducted by chemiluminescence luminal reagents (Super signal west pico trial kit, PIERCE). Meanwhile, DBP, encoded by E2 gene of adenovirus, was also applied as a control in HEK293 cells. Besides, PK15 cells were also inoculated with four recombinant adenoviruses at MOI of 100 to test Cap expression. In the western blot for testing the immune sera, pET-32a-ORF2 was used as the PCV2 antigen.

Indirect immunofluorescence assay (IFA). Thirty hours after the infection by recombinant adenoviruses, the culture plates were 
washed with $0.05 \%$ Tween-20 in PBS (PBS-T) three times, and fixed with cold ethanol for $15 \mathrm{~min}$ on ice. After washing three times, the cells were incubated with rabbit anti-PCV2 serum at $37^{\circ} \mathrm{C}$ for $1 \mathrm{hr}$. The cells were washed three times and stained with goat anti-rabbit IgG antibodies conjugated with FITC (Boshide) at $37^{\circ} \mathrm{C}$ for $1 \mathrm{hr}$. Fluorescence was determined by a fluorescent microscope.

Mice immunization with recombinant adenoviruses. Ninety Kunming mice (6-week-old) were purchased from the Animal Center, The Fourth Military Medical University, Xi'an, China. Animal experiments were done according to the Animal Ethics Committee of the North West Agriculture and Forestry University (protocol number P15026). Mice were randomly divided into six groups and every group contained 15 mice. Mice in group 1-4 were immunized subcutaneously with $10^{8} \mathrm{TCID}_{50}$ of Ad-C, Ad-A-C, Ad-C-W, and Ad-A-C-W, respectively; mice in group 5 were immunized subcutaneously with $10^{8} \mathrm{TCID}_{50}$ of wild-type adenovirus; mice in group 6 were treated with PBS as control. Booster immunization was conducted 14 days later under the same conditions. Sera of three mice from each group were collected on day $0,14,28,35,42,49$ and 56 after first vaccination for detecting specific antibody levels and neutralizing antibody levels by indirect enzyme-linked immunosorbent assay (iELISA), western blot and virus neutralization assay (VN). On day 28, 35, 42, 49 and 56 after first immunization, the spleens of three mice in every group were excised and detected by further lymphocyte proliferation assay and cytokines release assay.

iELISA. PET-32a-ORF2, containing ORF2 gene without the nuclear localization signal, was prepared in our lab (data not shown). The recombinant His-Cap protein was purified through His. Bind purification kit (Novagen, USA) was used for coating by $5 \mu \mathrm{g} / \mathrm{ml}$ of proteins into 96 -well plates. The plates were incubated with $5 \%$ fat-free milk in PBS. Sera were diluted in two-fold, beginning with $1: 100$. Then the plates were incubated at $37^{\circ} \mathrm{C}$ for $1 \mathrm{hr}$. After washing three times, goat anti-mouse IgG antibodies conjugated with HRP were added and incubated at $37^{\circ} \mathrm{C}$ for $1 \mathrm{hr}$. Meanwhile, sera from group 5 and 6 were applied as negative controls. The results were determined by the ratio of optical density at A490 conducted by serum samples divided by negative control. A ratio value higher than 2.1 was regarded as being positive. The titers were regarded as the highest dilution of antibody producing 2.1 ratio values.

Virus neutralization assay (VN). PCV2 neutralizing antibodies were tested on day 14, 28, 35, 42, 49 and 56 after first vaccination by VN. The sera were diluted in Roswell Park Memorial Institute1640 (RPMI-1640) (pH 7.2) in two-fold, beginning with 1:2. PCV2 $\left(1000 \mathrm{TCID}_{50} / \mathrm{ml}\right)$ was equally added to the diluent and incubated at $37^{\circ} \mathrm{C}$ for $1 \mathrm{hr}$. Mixture was added onto a 96 -well plate with $50-70 \%$ confluent PK15 cells as in the previous study (Blanchard et al., 2003). After $72 \mathrm{hr}$, the cells were fixed with cold ethanol for $15 \mathrm{~min}$ at $4^{\circ} \mathrm{C}$, incubated with antibody to PCV2 and stained with FITC-conjugated goat anti-rabbit IgG antibodies. Titers were considered as the reciprocal of the last serum dilution at $70 \%$ or greater fluorescent focus reduction in inoculated cell cultures with a fluorescent microscope.

Lymphocyte proliferation assay. Splenocyte preparations were done according to the previous study (Kim et al., 2004). On day $28,35,42,49$ and 56 after first vaccination, lymphocytes were separated aseptically from the spleens of three mice with mouse lymphocyte separation medium (DAKEWE, China) following the standard procedures. Lymphocytes were seeded onto a 96 -well plate with the concentration of $2 \times 10^{6}$ cells $/ \mathrm{ml}$. Then the cultures were stimulated for $68 \mathrm{hr}$ with either Concanavalin A (ConA; Sigma, USA; $5 \mu \mathrm{g} / \mathrm{ml})$ as positive control, Cap protein $(20 \mu \mathrm{g} / \mathrm{ml})$ as the stimulant, or RPMI-1640 as negative control. Then $20 \mu \mathrm{l}$ of MTT (3-[4, 5-dimethylthiazol-2-y]-2, 5-diphenyltetrasodium bromide Tetrazolium; Sigma; $5 \mathrm{mg} / \mathrm{ml}$ in PBS) was added per well with a further incubation for $4 \mathrm{hr}$. Hundred micro liters of dimethyl sulfoxide (DMSO) were added per well to stop the reaction. The absorbance of A570 was detected and the stimulation index (SI) was determined as: $\mathrm{SI}=$ mean Absorbance of Cap-stimulated cells/ mean Absorbance of unstimulated cells.

Cytokines release assay. Lymphocytes were separated as mentioned above on day 28, 35, 42, 49 and 56 after first vaccination. Then the lymphocytes were seeded onto 96-well plates with $2 \times 10^{6}$ cells/ml. Triplicate wells with RPMI-1640 alone and $2 \mu \mathrm{g}$ of Cap protein were added for $72 \mathrm{hr}$. Supernatants were collected. Titers of IFN- $\gamma$ and IL- 4 were detected by mice IFN- $\gamma$ and IL- 4 ELISA kits

Table 1. Primers for PCR amplification used in this study

\begin{tabular}{lllc}
\hline Segments & Primers & Sequences (from 5' to 3') & Product sizes/bp \\
\hline puc-Cap & puc-Cap-F & TTATCTAGAATGAATGGCTTTTTCAACAGCCGCCT & 579 \\
& puc-Cap-R & ATTGTCGACATGGCATCTTCAACACCCGCC & 579 \\
PS-C & PS-C-F & AATCTCGAGATGAATGGCTTTTTCAACAGCCG & \\
& PS-C-R & CCGGATATCTTAGGGTTTTAGTGGGGGGTCTTTC & 1412 \\
PS-A-C & PS-A-C-F & AATCTCGAGGTAAGTACCGCCTATAGACTCTATAGGCAC & 1164 \\
& PS-A-C-R & CGGGATATCTTAGGGTTTTAGTGGGGGGTCTT \\
PS-C-W & PS-C-W-F & AATCTCGAGATGAATGGCTTTTTCAACAGCCGC & 1994 \\
& PS-C-W-R & ATTGATATCGCCCAAAGGGAGATCCGACTCGT \\
PS-A-C-W & PS-A-C-W-F & AATCTCGAGGTAAGTACCGCCTATAGACTCTATAGGCAC & \\
& PS-A-C-W-R & TCAGATATCGCCCAAAGGGAGATCCGACTC & \\
\hline
\end{tabular}

The restriction sites are underlined. 


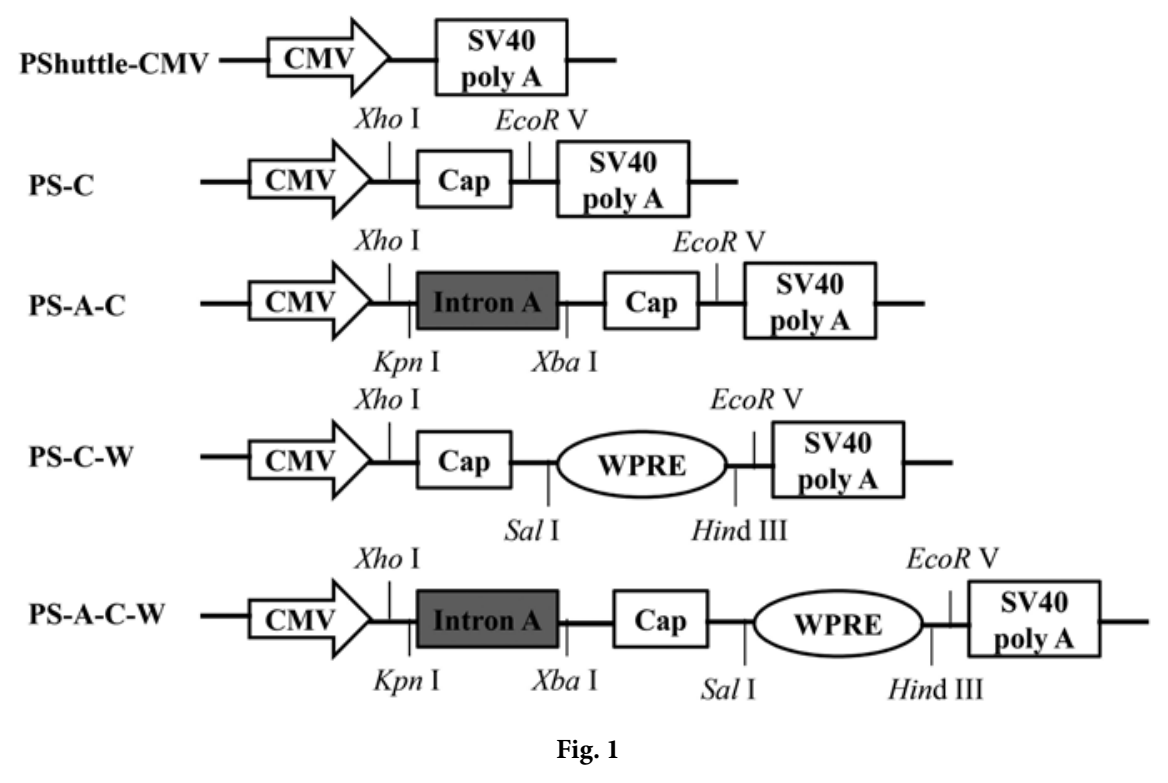

Combinations of PCV2 ORF2 expression cassettes by modification of the original PShuttle-CMV vector Intron A (the largest intron of the human cytomegalovirus) was inserted upstream of the Cap. The WPRE (woodchuck hepatitis virus post-transcriptional regulatory element) was inserted upstream of the SV40 poly A (simian vacuolating virus polyadenylation signal) and downstream of the PShuttle-CMV are three stop codons. The locations of the restriction enzyme sites are indicated.

(ExCell Bio, China) following standard procedures. The concentrations of mice IFN- $\gamma$ and IL- 4 in the supernatants were evaluated by the standard curves.

Statistical analysis. All data were conducted as the mean + standard deviation (SD). One-way ANOVA and student's $t$-test were used to assess the statistical differences among groups with SPSS 19.0 software (SPSS Inc., USA). A value of ${ }^{\star} P<0.05$ was regarded as significant.

\section{Results}

\section{Vector construction and characterization}

In this study, PShuttle-CMV with PCV2 ORF2 gene was modified (Fig. 1). The constructed plasmids were verified by PCR and digested with PacI. Two fragments of about 30 (a)

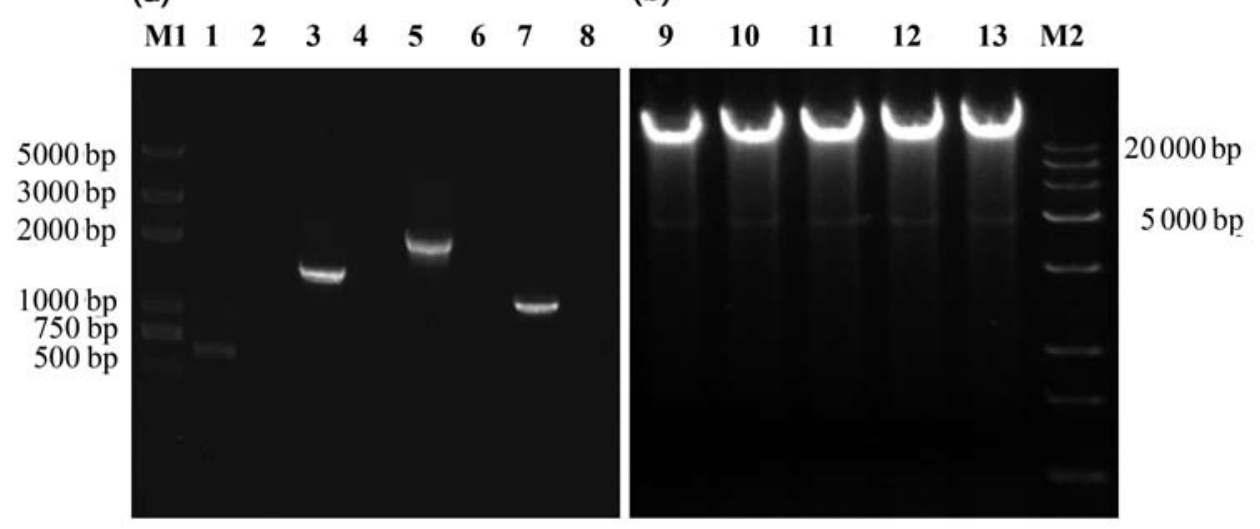

Fig. 2

The recombinant plasmids were identified by PCR and digested with PacI enzyme

(a) The recombinant plasmids were identified by PCR. M1, 2K Plus Marker; lane 1, PS-C; lane 3, PS-A-C; lane 5, PS-A-C-W; lane 7, PS-C-W; lane 2, 4, 6, 8, negative control. (b) The recombinant plasmids were digested with PacI enzyme. M2, 15K Plus Marker; lane 9, rAd-C; lane 10, rAd-A-C; lane 11, rAd-C-W; lane 12, rAd-A-C-W; lane 13, rAd-wild. 


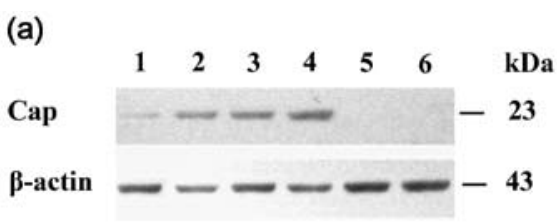

(c)

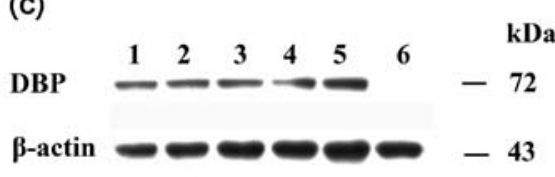

(b)



(d)

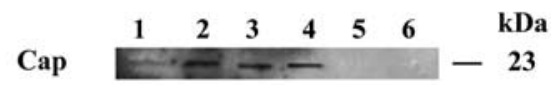

Fig. 3

Western blot analyses of Cap protein expression by different recombinant adenoviruses and Cap antibody levels in the mice immunized with different recombinant adenoviruses

(a) Western blot analyses of different recombinant adenoviruses expressing Cap protein in HEK293 cells. (b) Western blot analyses of different recombinant adenoviruses expressing Cap protein in PK15 cells. (c) Western blot of adenoviral DBP in HEK293 cells as a control of adenoviral presence. (d) Western blot of PCV2 Cap protein with sera of mice immunized with different recombinant adenoviruses. Lane 1, Ad-C; lane 2, Ad-A-C; lane 3, Ad-C-W; lane 4, Ad-A-C-W; lane 5, wild-type adenovirus; lane 6, PBS. The expression of $\beta$-actin is below as the internal control.

$\mathrm{kb}$ and about $5.0 \mathrm{~kb}$ were observed as expected (Fig. 2). At 10 days post-transfection of five recombination plasmids (including the rAd-wild) into HEK293 cells, CPE was observed. Five recombinant adenoviruses were titrated by plaque purification three times, and named as Ad-C, AdA-C, Ad-C-W, Ad-A-C-W and wild-type adenovirus. The viral titers of five recombinant adenoviruses were all about $10^{10} \mathrm{TCID}_{50} / \mathrm{ml}$.

\section{Expression of Cap protein in HEK293 cells}

HEK293 cells were infected with Ad-C, Ad-A-C, Ad-C-W, Ad-A-C-W and wild-type adenovirus at MOI of 20 for $30 \mathrm{hr}$.
Western blot showed that PCV2 ORF2 gene encoding Cap was observed in Ad-C, Ad-A-C, Ad-C-W and Ad-A-C-W infected cells, but no corresponding band has appeared in wildtype adenovirus infected or PBS mock treated HEK293 cells. In addition, the results showed that Cap protein expression levels were higher in modified recombinant adenoviruses (Ad-A-C, Ad-C-W, Ad-A-C-W) than that in unmodified recombinant adenovirus (Ad-C), and Cap expression levels were also different among modified recombinant adenoviruses (Fig. 3a). Modified adenovirus Ad-A-C-W with Intron $A$ and WPRE showed the highest Cap expression levels. Cap expression in PK15 cells was similar as the results of Cap expression in HEK293 cells (Fig. 3b). However, adenoviral DBP (a)

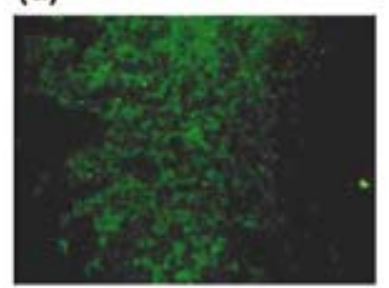

(d)

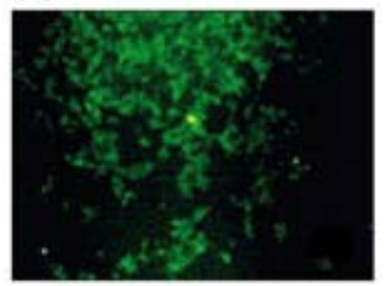

(b)

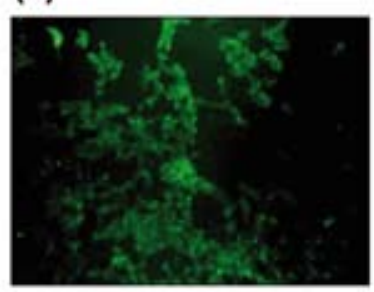

(e)

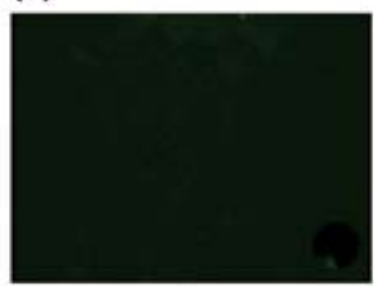

Fig. 4 (c)

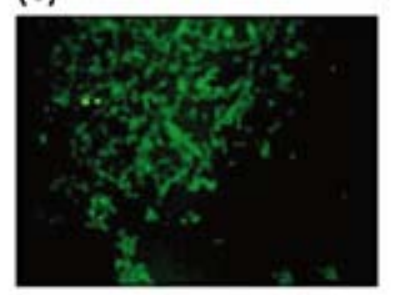

(f)

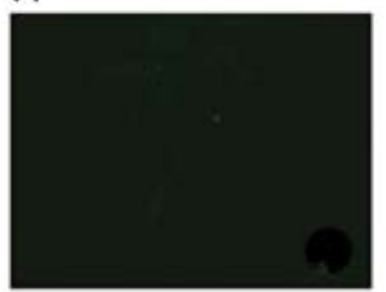

Expression of the encoded Cap protein in infected HEK293 cells by IFA using specific antiserum to PCV2 Fluorescence was detected in HEK293 cells infected with Ad-C (a), Ad-A-C (b), Ad-C-W (c), and Ad-A-C-W (d). No fluorescence was detected in wildtype adenovirus (e) and PBS-infected 293 cells (f). 


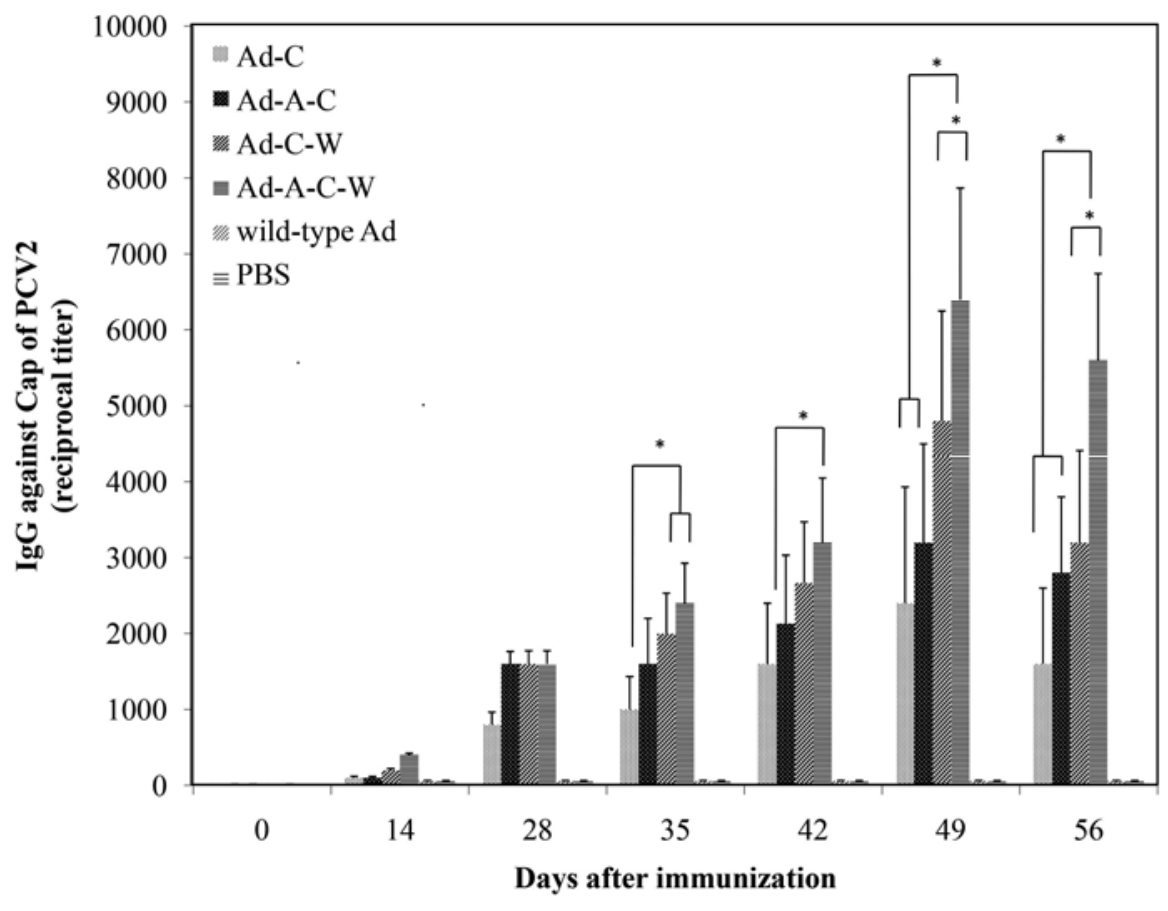

Fig. 5

iELISA assay for PCV2-specific antibodies of sera from the mice immunized with different adenoviruses

The results were expressed as the ratio of A490 produced by the serum samples compared to negative control serum. Sera, giving a ratio value higher than 2.1 were considered to be positive sera. The titers were expressed as the highest dilution of antibody producing 2.1 ratio values. Data are presented as the mean \pm S.D. ${ }^{*} P<0.05$.

expression did not increase in modified adenoviruses with Intron A and WPRE (Fig. 3c). In indirect immunofluorescence assay, PCV2 Cap protein could be specifically detected in recombinant adenoviruses infected HEK293 cells, but not in the wild-type adenovirus (Fig. 4).

\section{Detection of specific antibodies to PCV2 by iELISA}

PCV2 Cap specific antibody titers were measured in different recombinant adenovirus vaccinated mice on $14,28,35$, $42,49,56$ days after first vaccination. The antibodies against PCV2 were detected in recombinant adenovirus treated mice on day 14 after first vaccination, and reached 1:2,400, 1:3,200, $1: 4,800$ and 1:6,400 in mice injected with Ad-C, Ad-A-C, Ad-C-W and Ad-A-C-W on day 49 after first immunization, respectively (Fig. 5). Among these groups, Ad-A-C-W vaccinated group showed highest antibody titers, followed by Ad-C-W, Ad-A-C and Ad-C groups. However, mice vaccinated with wild-type adenovirus or PBS did not contain Cap specific antibody throughout the whole experiments.

Next, the specificity of antibody against Cap protein in each group was determined by western blot. The results showed that sera from group Ad-C, Ad-A-C, Ad-C-W and Ad-A-C-W could recognize the Cap protein on day 28 after first vaccination, while sera from groups of wild-type adenovirus and PBS inoculated mice could not (Fig. 3d). However, mice in all inoculated groups did not show obvious clinical signs throughout the whole experiment.

\section{Virus neutralization assay (VN)}

The neutralizing activity of sera from inoculated mice against Cap proteins were measured in PK15 cells challenged with PCV2. The sera from mice vaccinated with recombinant adenoviruses could prevent PK15 cells from PCV2 infection. On day 49 after first vaccination, neutralizing antibody titers reached 1:16, 1:20, 1:24 and 1:32 in Ad-C, Ad-A-C, Ad-C-W and Ad-A-C-W groups, respectively, but sera from wild-type adenovirus vaccinated mice or PBS-treated mice kept very low level in neutralizing activity (Fig. 6).

\section{Lymphocyte proliferation assay}

Lymphocyte proliferative response of mice was measured on day 28, 35, 42, 49, 56 after first immunization. As shown in Fig. 7, the proliferative response of different immunized groups increased after the immunization, and the SI of every immunized group reached highest level on day 49 after first 


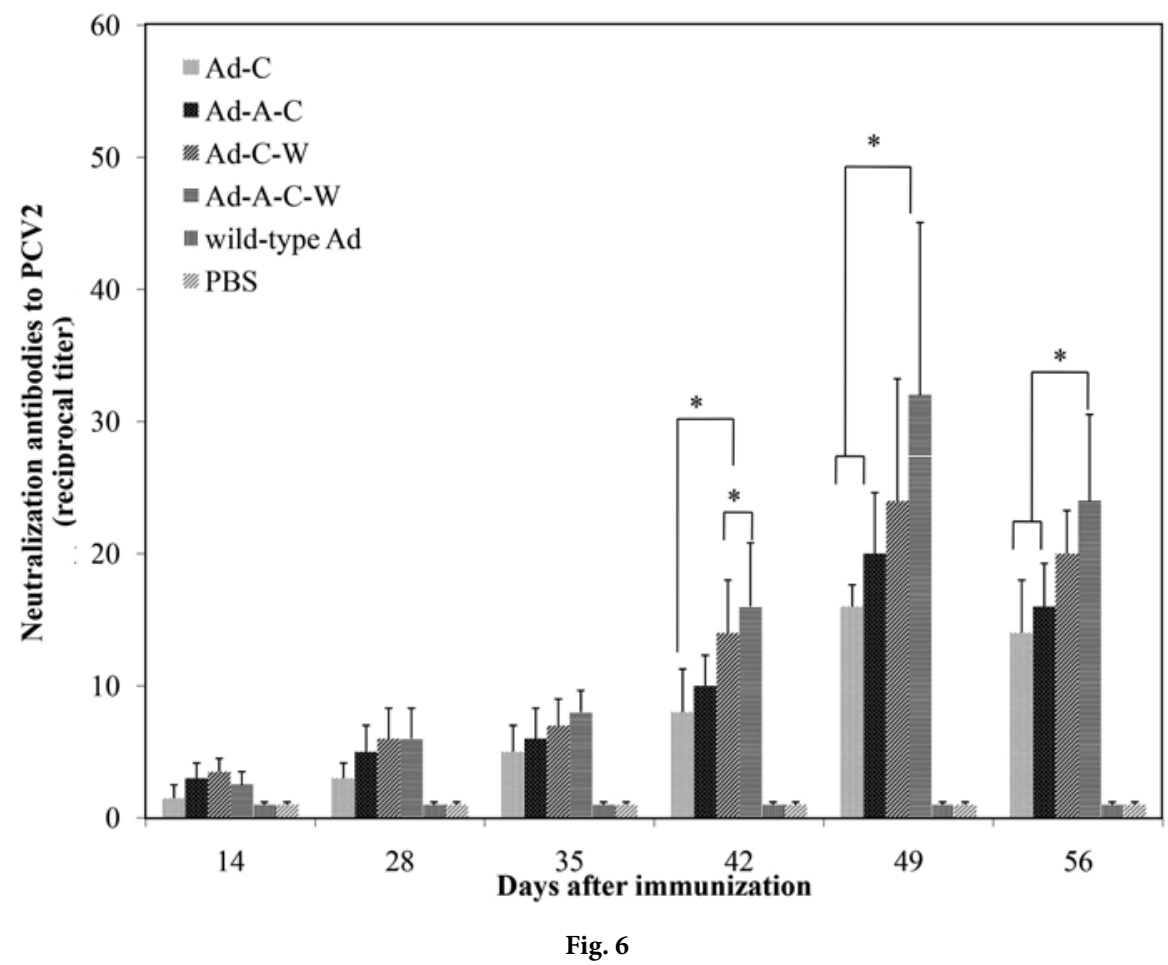

Virus neutralization assay of sera from the mice immunized with different adenoviruses Neutralizing titers are reciprocals of the highest dilution of serum which yielded a 70\% reduction in virus infectivity. Data are presented as the mean \pm S.D. ${ }^{*} P<0.05$.

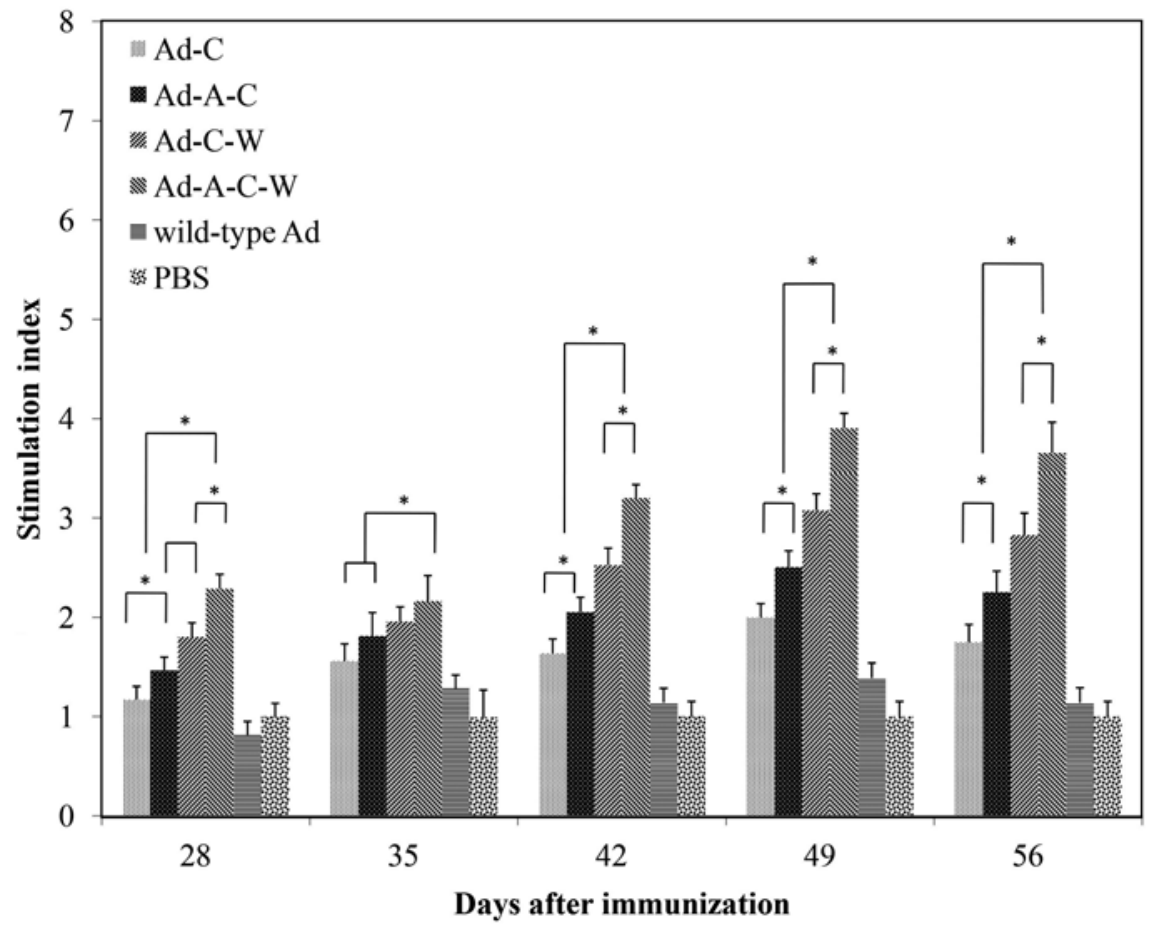

Fig. 7

Cell proliferation levels of splenocytes after in vitro stimulation

After immunization with adenoviruses Ad-C, Ad-A-C, Ad-C-W and Ad-A-C-W, wild-type adenovirus and PBS, three mice of each group were sacrificed and splenocytes were pooled for the lymphocyte proliferation assay. Data are presented as the mean \pm S.D. ${ }^{\star} P<0.05$. 

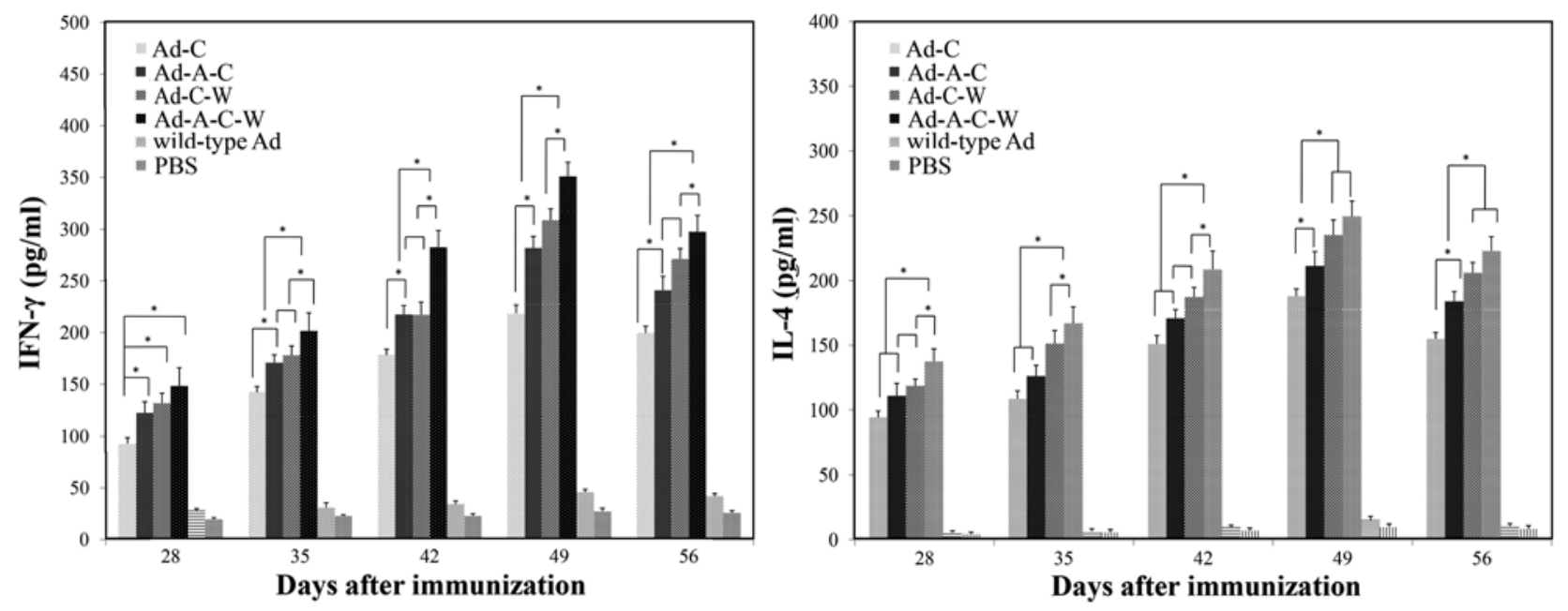

Fig. 8

Levels of IFN- $\gamma$ and IL-4 produced from lymphocytes in immunized mice

On day $28,35,42,49$ and 56 after primary immunization, mice lymphocytes from each group were harvested, cultured in 96-well plates and stimulated with purified Cap protein. IFN $-\gamma$ and IL-4 production in the supernatant were analyzed by ELISA. Data represent the mean \pm S.D. ${ }^{*} P<0.05$.

immunization. Besides, on day 49 after first immunization, mice inoculated with adenovirus Ad-A-C-W showed higher SI than the other three groups $\left({ }^{\star} P<0.05\right)$, SI of group AdA-C were significantly higher than group Ad-C $\left({ }^{\star} P<0.05\right)$, but lower than group Ad-C-W $\left({ }^{*} P<0.05\right)$.

\section{Cytokine production}

On day $28,35,42,49$, and 56 after first immunization, the secretion of IFN- $\gamma$ and IL- 4 was measured in the stimulated lymphocytes to evaluate the Th1-type and Th2-type responses of immunized mice. IL- 4 and IFN- $\gamma$ production of stimulated lymphocytes from Ad-C, Ad-A-C, Ad-C-W and Ad-A-C-W vaccinated mice was higher than from wild-type adenovirus vaccinated mice or PBS-treated mice $\left({ }^{\star} P<0.05\right)$. Cytokine titers of four modified recombinant adenovirus immunized groups reached highest level on day 49 after first immunization. On day 49 after first immunization, the levels of IL- 4 and IFN- $\gamma$ induced by group Ad-A-C was significantly higher than Ad-C $\left({ }^{\star} P<0.05\right)$, but lower than Ad-C-W $\left({ }^{\star} P<0.05\right)$. Group Ad-A-C-W showed significantly higher levels of IFN- $\gamma$ than other groups $\left({ }^{*} P<0.05\right)$. Although the level of IL-4 of group Ad-A-C-W was significantly higher than Ad-C and Ad-A-C $\left({ }^{\star} P<0.05\right)$, it was slightly higher than Ad-C-W $\left({ }^{\star} P>0.05\right)$ (Fig. 8$)$.

\section{Discussion}

Adenovirus vector, one of the most widely-used live virus vectors, has many advantages such as high transduction efficiency and wide tropism (Bergelson et al., 1997; Tomko et al., 1997). Adenovirus vector system against PCV2 has been investigated, but has limited efficacy (Wang et al., 2006; Wang et al., 2007). So it is necessary to improve the immune responses of PCV2 Cap adenovirus-based vaccine. In the previous study, Intron A and WPRE have been demonstrated to increase protein expression from an adenovirus vector $(\mathrm{Li}$ et al., 2012; Mariati et al., 2010; Xu et al., 2002, 2003), but not including PCV2 Cap. In the present study, we constructed the modified adenovirus with Intron A and WPRE and found that the recombinant adenovirus modified with both Intron A and WPRE could significantly improve the immunogenic expression in vitro and immune responses in mice.

Adenovirus vector system has been used to express many proteins, including the Cap protein. However, adenovirus vector system expressing Cap protein has not been put into practice in field and no relevant commercial adenovirus vaccine has been available yet. The main reason is that many proteins expressed by adenovirus play an adverse impact on immunogenicity of the vaccine (Yang et al., 1995). To solve this problem, several studies have been conducted by coexpressing cytokines to increase the protein expression (Liu et al., 2011; Wang et al., 2009). However, another optional approach is to improve the expression of target protein in adenovirus. Intron A is a strong transcriptional regulatory element which can improve protein expression by enhancing RNA polyadenylation and/or nuclear transport (Huang and Gorman, 1990). To improve the expression of Cap protein, we inserted Intron A into the adenovirus vector and evaluated the immune responses in mice. In vitro, protein expression assays showed that Intron A could substantially improve the Cap 
expression in HEK293 cells. In addition, adenovirus vector modified with Intron A could induce stronger humoral and cellular immune responses in mice than adenovirus without Intron A. These data demonstrated that Intron A could increase Cap expression and enhance the immunogenicity of adenovirus vector vaccines against PCV2.

Improvement strategies of expression vectors contain two important features, strong promoters and polyadenylation sequences (Hartikka et al., 1996). WPRE is a cis-acting element that could increase mRNA stability and mRNA extranuclear transport, resulting in increased mRNA levels in cytoplasm and protein expression (Zufferey et al., 1999). In this study, we evaluated the role of WPRE in Cap expression and the immunogenicity of adenovirus vector vaccines in mice. The results showed that the WPRE inserted in Ad-C-W significantly increased the expression of Cap and resulted in an increased humoral and cellular immune responses in mice compared to Ad-C without WPRE. Furthermore, AdA-C-W elicited the highest immune responses compared to Ad-A-C or Ad-C-W.

Though our study showed that Intron A and WPRE could improve the immune responses of adenovirus vector system expressing PCV2 Cap, the enhancing effect was not so satisfying in mice experiment. The specific antibody titers and neutralizing antibody titers of Ad-A-C-W vaccinated group was only 2.6 fold and 2 fold that of Ad-C vaccinated group on day 49 after first immunization. The results of lymphocyte proliferation responses and cytokine release assay were also not satisfying. The possible reason for lower efficiency of immune response was that the immune dose of adenovirus may be higher in mice. $10^{8} \mathrm{TCID}_{50}$ of adenovirus may induce the mouse's immune response to the limit. So the function of Intron A and WPRE on capsid expression just showed modest enhancing effect in Cap-induced immune response. The results of western blot analyses of different recombinant adenoviruses expressing Cap protein in PK15 cells also proved this supposition. Our study showed that Intron A and WPRE could increase the immune responses of PCV2 Cap adenovirus vector vaccine in mice to some extent, but it is still needed to further improve efficacy of adenovirus vaccine with some other measures.

In conclusion, modified recombinant adenoviruses containing Cap protein elicited enhanced immune responses in mice. Our data showed that Intron A and WPRE were helpful in enhancing the immune responses of adenovirus vector system expressing Cap protein, and they could work together both in vitro and in vivo. The results in our research highlight the possibility of decreasing the adverse effects of adenovirus vector on immune responses and increasing the potential value of adenovirus vector system against PCV2. Currently, the work to test the immunogenicity and protective efficacy of our modified recombinant adenoviruses in pigs is under way.
Acknowledgements. This research was supported by the grant from Key Scientific and Technological Innovation Team in Shaanxi province (2013KCT-28).

\section{References}

Beach NM, Meng XJ (2012): Efficacy and future prospects of commercially available and experimental vaccines against porcine circovirus type 2 (PCV2). Virus Res. 164, 33-42. http://dx.doi.org/10.1016/j.virusres.2011.09.041

Benihoud K, Yeh P, Perricaudet M (1999): Adenovirus vectors for gene delivery. Curr. Opin. Biotechnol. 10, 440-447. http:// dx.doi.org/10.1016/S0958-1669(99)00007-5

Bergelson JM, Cunningham JA, Droguett G, KurtJones EA, Krithivas A, Hong JS, Horwitz MS, Crowell RL, Finberg RW (1997): Isolation of a common receptor for Coxsackie B viruses and adenoviruses 2 and 5. Science 275, 1320-1323. http://dx.doi.org/10.1126/science.275.5304.1320

Bissonnette N, Gilbert I, Levesque-Sergerie JP, Lacasse P, Petitclerc D (2006): In vivo expression of the antimicrobial defensin and lactoferrin proteins allowed by the strategic insertion of introns adequately spliced. Gene 372, 142-152. http:// dx.doi.org/10.1016/j.gene.2005.12.030

Blanchard P, Mahe D, Cariolet R, Keranflec'h A, Baudouard MA, Cordioli P (2003): Protection of swine against postweaning multisystemic wasting syndrome (PMWS) by porcine circovirus type 2 (PCV2) proteins. Vaccine 21, 4565-4575. http://dx.doi.org/10.1016/S0264-410$\underline{\mathrm{X}(03) 00503-6}$

Choi T, Huang M, Gorman C, Jaenisch R (1991): A generic intron increases gene expression in transgenic mice. Mol. Cell. Biol. 11, 3070-3074. http://dx.doi.org/10.1128/ MCB.11.6.3070

Douglas JT (2007): Adenoviral vectors for gene therapy. Mol. Biotechnol. 36, 71-80. http://dx.doi.org/10.1007/s12033007-0021-5

Ferreira TB, Alves PM, Aunins JG, Carrondo MJ (2005): Use of adenoviral vectors as veterinary vaccines. Gene Ther. 12, 73-83. http://dx.doi.org/10.1038/sj.gt.3302618

Hartikka J, Sawdey M, Cornefert-Jensen F, Margalith M, Barnhart K, Nolasco M, Vahlsing HL, Meek J, Marquet M, Hobart P, Norman J, Manthorpe M (1996): An improved plasmid DNA expression vector for direct injection into skeletal muscle. Hum. Gene Ther. 7, 1205-1217. http://dx.doi. org/10.1089/hum.1996.7.10-1205

Huang MTF, Gorman CM (1990): Intervening sequences increase efficiency of RNA 3' processing and accumulation of cytoplasmic RNA. Nucleic Acids Res. 18, 937-947. http:// dx.doi.org/10.1093/nar/18.4.937

Khayat R, Brunn N, Speir JA, Hardham JM, Ankenbauer RG, Schneemann A (2011): The 2.3-angstrom structure of porcine circovirus 2. J. Virol. 85, 7856-7862. http://dx.doi. org/10.1128/JVI.00737-11

Kim SJ, Sung HW, Han JH, Jackwood D, Kwon HM (2004): Protection against very virulent infectious bursal disease virus in chickens immunized with DNA vaccines. Vet. 
Microbiol. 101, 39-51. http://dx.doi.org/10.1016/j. vetmic.2004.03.009

Kovesdi I, Brough DE, Bruder JT, Wickham TJ (1997): Adenoviral vectors for gene transfer. Curr. Opin. Biotechnol. 8, 583589. http://dx.doi.org/10.1016/S0958-1669(97)80033-X

Li PY, Yu L, Wu XA, Bai WT, Li K, Wang HT, Hu G, Zhang L, Zhang FL, Xu ZK (2012): Modification of the adenoviral transfer vector enhances expression of the Hantavirus fusion protein $\mathrm{GnS} 0.7$ and induces a strong immune response in C57BL/6 mice. J. Virol. Met. 179, 90-96. http://dx.doi. org/10.1016/j.jviromet.2011.10.005

Liu G, Luo M, Chen R, Huang H, Pei D (2011): Construction and immunogenicity of recombinant adenovirus expressing ORF2 of PCV2 and porcine IFN gamma. Vaccine 29, 8677-8682. http://dx.doi.org/10.1016/j. vaccine.2011.08.118

Lv QZ, Guo KK, Zhang YM (2014): Current understanding of genomic DNA of porcine circovirustype 2. Virus Genes 49, 1-10. http://dx.doi.org/10.1007/s11262-014-1099-Z

Mankertz A, Domingo M, Folch JM, Lecann P, Jestin A, Segalés J, Chmielewicz B, Plana-Durán J, Soike D (2000): Characterisation of PCV-2 isolates from Spain, Germany and France. Virus Res. 66, 65-77. http://dx.doi.org/10.1016/ S0168-1702(99)00122-7

Mariati HSC, Yap MG, Yang Y (2010): Evaluating post-transcriptional regulatory elements for enhancing transient gene expression levels in CHO K1 and HEK293 cells. Protein Expr. Purif. 69, 9-15. http://dx.doi.org/10.1016/j. pep.2009.08.010

Misinzo G, Delputte PL, Meerts P, Lefebvre DJ, Nauwynck HJ (2006): Porcine circovirus 2 uses heparan sulfate and chondroitin sulfate B glycosaminoglycans as receptors for its attachment to host cells. J. Virol. 80, 3487-3494. http:// dx.doi.org/10.1128/JVI.80.7.3487-3494.2006

Nawagitgul P, Morozov I, Bolin SR, Harms PA, Sorden SD, Paul PS (2000): Open reading frame 2 of porcine circovirus type 2 encodes a major capsid protein. J. Gen. Virol. 81, 2281-2287. http://dx.doi.org/10.1099/0022-1317-819-2281

Niwa M, Rose SD, Berget SM (1990): In vivo polyadenylation is stimulated by the presence of an upstream intron. Genes Dev. 4, 1552-1559. http://dx.doi.org/10.1101/ gad.4.9.1552

Opriessnig T, Meng XJ, Halbur PG (2007): Porcine circovirus type2associated disease: update on current terminology, clinical manifestations, pathogenesis, diagnosis, and intervention strategies. J. Vet. Diagn. Invest. 19, 591-615. http://dx.doi. org/10.1177/104063870701900601

Shang SB, Jin YL, Jiang XT, Zhou JY, Zhang X, Xing G (2009): Fine mapping of antigenic epitopes on capsid proteins of porcine circovirus, and antigenic phenotype of porcine circovirus type 2. Mol. Immunol. 46, 327-334. http:// dx.doi.org/10.1016/j.molimm.2008.10.028

Sridhar S, Reyes-Sandoval A, Draper SJ, Moore AC, Gilbert SC, Gao GP, Wilson JM, Hill AV (2008): Single-dose protection against Plasmodium berghei by a simian adenovirus vector using a human cytomegalovirus promoter containing intron A. J. Virol. 82, 3822-3833. http://dx.doi. org/10.1128/JVI.02568-07

Thacker EE, Timares L, Matthews QL (2009): Strategies to overcome host immunity to adenovirus vectors in vaccine development. Expert Rev. Vaccines 8, 761-777. http:// dx.doi.org/10.1586/erv.09.29

Tomko PR, Xu R, Philipson L (1997): HCAR and MCAR: the human and mouse cellular receptors for subgroup $C$ adenoviruses and group B coxsackieviruses. Proc. Natl. Acad. Sci. USA 94, 3352-3356. http://dx.doi.org/10.1073/ pnas.94.7.3352

Wang X, Jiang W, Jiang P, Li Y, Feng Z, Xu J (2006): Construction and immunogenicity of recombinant adenovirus expressing the capsid protein of porcine circovirus 2 (PCV2) in mice. Vaccine 24, 3374-3380. http://dx.doi.org/10.1016/j. vaccine. 2005.12 .068

Wang X, Jiang P, Li Y, Jiang W, Dong X (2007): Protection of pigs against post-weaning multisystemic wasting syndrome by a recombinant adenovirus expressing the capsid protein of porcine circovirus type 2. Vet. Microbiol. 121, 215-224. http://dx.doi.org/10.1016/j.vetmic.2006.11.027

Wang XL, Li JX, Jiang P, Li YF, Basit ZS, Cao J, Wang XW (2009): GM-CSF fused with GP3 and GP5 of porcine reproductive and respiratory syndrome virus increased the immune responses and protective efficacy against virulent PRRSV challenge. Virus Res. 143, 24-32. http://dx.doi. org/10.1016/j.virusres.2009.02.017

Xu ZL, Mizuguchi H, Ishii-Watabe A, Uchida E, Mayumi T, Hayakawa T (2002): Strength evaluation of transcriptional regulatory elements for transgene expression by adenovirus vector. J. Controlled Release 81, 155-163. http:// dx.doi.org/10.1016/S0168-3659(02)00059-7

Xu ZL, Mizuguchi H, Mayumi T, Hayakawa T (2003): Woodchuck hepatitis virus post-transcriptional regulation element enhances transgene expression from adenovirus vectors. Biochimica et Biophysica Acta 1621, 266-271. http:// dx.doi.org/10.1016/S0304-4165(03)00078-3

Yang Y, Li Q, Ertl HC, Wilson JM (1995): Cellular and humoral immune responses to viral antigens create barriers to lung-directed gene therapy with recombinant adenoviruses. J. Virol. 69, 2004-2015.

Zufferey R, Donello JE, Trono D, Hope TJ (1999): Woodchuck hepatitis virus posttranscriptional regulatory element enhances expression of transgenes delivered by retroviral vectors. J. Virol. 73, 2886-2892. 